\title{
Agreement in late twentieth century Southern Hemisphere stratospheric temperature trends in observations and CCMVal-2, CMIP3 and CMIP5 models
}

Paul J. Young ${ }^{1,2,3}$, Amy H. Butler ${ }^{4}$, Natalia Calvo,6,7, Leopold Haimberger ${ }^{8}$, Paul J. Kushner $^{9}$, Daniel R. Marsh ${ }^{6}$, William J. Randel ${ }^{6}$ and Karen H. Rosenlof ${ }^{2}$

${ }^{1}$ Cooperative Institute for Research in the Environmental Sciences (CIRES), University of Colorado, Boulder, Colorado, USA.

2 Chemical Sciences Division, NOAA Earth System Research Laboratory, Boulder, Colorado, USA.

${ }^{3}$ Now at Lancaster Environment Centre, Lancaster University, Lancaster, UK

${ }^{4}$ NOAA Climate Prediction Center, College Park, Maryland, USA.

${ }^{5}$ Departamento de Física de la Tierra II, Universidad Complutense de Madrid, Madrid, Spain.

${ }^{6}$ National Center for Atmospheric Research, Boulder, Colorado, USA.

${ }^{7}$ Advanced Study Program, NCAR, Boulder, Colorado, USA

${ }^{8}$ Department for Meteorology and Geophysics, University of Vienna, Vienna, Austria.

${ }^{9}$ Department of Physics, University of Toronto, Toronto, Ontario, Canada.

This article has been accepted for publication and undergone full scientific peer review but has not been through the copyediting, typesetting, pagination and proofreading process which may lead to differences between this version and the Version of Record. Please cite this article as an 'Accepted Article', doi: 10.1002/jgrd.50126 


\section{(Abstract)}

We present a comparison of temperature trends using different satellite and radiosonde observations and climate (GCM) and chemistry-climate model (CCM) output, focusing on the role of photochemical ozone depletion in the Antarctic lower stratosphere during the second half of the twentieth century. Ozone-induced stratospheric cooling peaks during November at an altitude of approximately $100 \mathrm{hPa}$ in radiosonde observations, with $1969-1998$ trends in the range -3.8 to $-4.7 \mathrm{~K} / \mathrm{dec}$. This stratospheric cooling trend is more than $50 \%$ greater than the previously estimated value of $-2.4 \mathrm{~K} / \mathrm{dec}$ [Thompson and Solomon, 2002], which suggested that the CCMs were overestimating the stratospheric cooling, and that the less complex GCMs forced by prescribed ozone were matching observations better. Corresponding ensemble mean model trends are $-3.8 \mathrm{~K} /$ dec for the CCMs, $-3.5 \mathrm{~K} / \mathrm{dec}$ for the CMIP5 GCMs, and $-2.7 \mathrm{~K} / \mathrm{dec}$ for the CMIP3 GCMs. Accounting for various sources of uncertainty - including sampling uncertainty, measurement error, model spread, and trend confidence intervals - observations, and CCM and GCM ensembles are consistent in this new analysis. This consistency does not apply to every individual that comprises the GCM and CCM ensembles, and some do not show significant ozone-induced cooling. Nonetheless, analysis of the joint ozone and temperature trends in the CCMs suggests that the modeled cooling/ozone-depletion relationship is within the range of observations. Overall, this study emphasizes the need to use a wide range of observations for model validation, as well as sufficient accounting of uncertainty in both models and measurements. 
Keywords: RICH-obs, RICH-tau, RAOBCORE, IUK, HadAT2, MSU, CCMVal, IPCC, CMIP

\section{Introduction}

Observations [e.g., Randel and Wu, 1999; Thompson and Solomon, 2002] and models [Gillett et al., 2011; Polvani et al., 2011] suggest that the strong decreasing trend in late $20^{\text {th }}$ century springtime Antarctic stratospheric ozone [Solomon, 1999] is responsible for most of the co-located and contemporaneous cooling trend [see also Forster et al., 2010]. Correctly modeling the stratospheric response to ozone depletion is essential to understand the magnitude of its impacts, as well as to probe the processes that drive those impacts. The influence of ozone depletion is felt far beyond the Antarctic stratosphere, and is likely apparent in modulations of the global stratospheric circulation [Garny et al., 2009; Mclandress and Shepherd, 2009], as well as in changes in the Southern Hemisphere (SH) troposphere [e.g., Gillett and Thompson, 2003; Son et al., 2010; Thompson et al., 2011], perhaps even extending to the subtropics [Kang et al., 2011].

Investigating the climate role of ozone changes was a goal of the second ChemistryClimate Model Validation (CCMVal-2) project [Eyring et al., 2008]. Analysis of the chemistry-climate model (CCM) temperature trends from CCMVal-2 [Baldwin et al., 2010] suggested that, on average, the modeled temperature trends associated with Antarctic ozone depletion were too strongly negative, when compared to the radiosonde trends calculated by Thompson and Solomon [2002] (hereafter TS02). Moreover, the analysis found that an ensemble of climate models, from the World Climate Research Programme's (WCRP) Coupled Model Intercomparison Project phase 3 (CMIP3) multi- 
model dataset [Meehl et al., 2007], matched the same observed trend estimates better, despite their far more limited representation of the stratosphere and their exclusion of chemical processes important for ozone.

Here this temperature trend comparison is revisited, presenting an intercomparison of modeled Antarctic temperature trends and those derived from a variety of observational datasets, beyond those presented by TS02. Although the focus is on trends from CCMVal-2, these are compared alongside the CMIP3 dataset, as used throughout the Intergovernmental Panel on Climate Change (IPCC) Fourth Assessment Report (AR4) [IPCC, 2007], as well as the CMIP5 dataset [Taylor et al., 2012], which will be used for the IPCC Fifth Assessment Report (AR5). Overall, the results suggest that there is broad consistency between the observed and the ensemble mean modeled ozone-related cooling, although the magnitude varies between different models [Austin et al., 2009] and between different observations [Randel et al., 2009], and is also sensitive to the time period under consideration.

\section{Model and observational data}

Table 1 summarizes the model, radiosonde and satellite observational temperature data used. For the radiosondes, whereas IUK and HadAT2 are already provided as monthly mean data, monthly means for the RAOBCORE and RICH datasets were calculated from daily data (averaging both the $00 \mathrm{Z}$ and $12 \mathrm{Z}$ soundings for each station, for better temporal coverage), using only stations with $<20 \%$ missing data at $100 \mathrm{hPa}$ (for the period 1969-1998; same as TS02). Using this criterion means that 10 of the possible 18 station data were used. Both the RICH-obs and RICH- $\tau$ datasets have 32 ensemble 
members, derived by varying parameters in the adjustment process [see Haimberger et al., 2012]. Here only the means of the 32 member ensembles are considered, although we note that there is good agreement between the polar cap mean $\left(>65^{\circ} \mathrm{S}\right) 1969-1998$ November $100 \mathrm{hPa}$ trends calculated using the individual ensemble members, with variability less than $0.05 \mathrm{~K} / \mathrm{dec}$ (1 standard deviation).

Figure 1 shows the location of the stations for each radiosonde dataset, highlighting in red those stations that were included in the analysis of TS02 (the trends at the stations are discussed in Section 3). As well as differing in the time period covered and number of stations south of $65^{\circ} \mathrm{S}$, each radiosonde dataset uses different methods to adjust the temperature time series, in order to account for any artificial shifts, such as from instrument or procedural changes. Furthermore, both the HadAT2 and IUK data stop at $30 \mathrm{hPa}$, whereas the RICH and RAOBCORE data extend to $10 \mathrm{hPa}$. Free [2011] showed the differences between many of the same datasets for tropical temperature trends. Further details concerning the radiosonde datasets and stations can be found in the supplementary material (Table S1).

Lower stratospheric satellite brightness temperature data from the Microwave Sounding Unit (MSU TLS) also form part of the analysis. The weighting function for the MSU TLS data covers a broad vertical layer centered on $\sim 80 \mathrm{hPa}$, with the half-power width extending from 150-50 hPa [see Randel et al., 2009, their Fig. 1]. This weighting function was applied to the radiosonde and model data for part of the analysis. The MSU TLS data give complete zonal coverage, but there are no data poleward of $82.5^{\circ} \mathrm{S}$. 
Monthly zonal mean temperature and ozone data from the CCMVal-2 models were taken from the REF-B1 experiment, which was configured to reproduce the composition of the atmosphere from 1960 to 2006 [Morgenstern et al., 2010]. Ozone output was not available for the AMTRAC3 and UMETRAC models. CMIP3 monthly zonal mean temperature data were taken from the 20C $3 \mathrm{M}$ experiment, which also aimed to reproduce past climate (from the pre-industrial to the year 2000) [Meehl et al., 2007]. For CMIP3, our study leaves out CNRM-CM3 and UKMO-HadCM3, as these models have incomplete temperature data (missing data in the lower stratosphere), as well as UKMOHadCM3 having prescribed ozone trends twice as large as observed [Karpechko et al., 2008]. GISS-EH and GISS-ER had an erroneously low ozone forcing [Miller et al., 2006], though these models are still included in this analysis (see Figure S1). The CMIP3 models were sub-divided into those that included time varying prescribed ozone data ("CMIP3 w/ozone") and those that did not ("CMIP3 no ozone"), as has been done previously [e.g., Cordero and Forster, 2006; Cai and Cowan, 2007; Karpechko et al., 2008]. Monthly zonal mean temperatures from the CMIP5 historical experiment, covering the pre-industrial to 2005 [see Taylor et al., 2012 and refs. therein], were also considered. All of these models used some form of time-varying ozone, either calculating concentrations interactively (in the manner of a CCM) or through using a prescribed dataset (the dataset developed by Cionni et al. [2011] was recommended); Eyring et al. [Long-term changes in tropospheric and stratospheric ozone and associated climate impacts in CMIP5 simulations, submitted to Journal of Geophysical ResearchAtmospheres, 2012] describe further details related to the ozone concentrations in the 
CMIP5 models. More information on the individual models from the CMIP3, CMIP5 and CCMVal-2 datasets can be found in the supplementary material (Tables S2-S4).

For the three model datasets, where there was more than one realization available for a given model, the intra-model ensemble mean was first determined before calculating the overall dataset ensemble mean (i.e. each model was weighted equally).

Trends are mainly considered over the 30-year period 1969-1998, for consistency with TS02 and Baldwin et al. [2010], and over the 21-year period 1979-1999, the period that all observations and models have in common (Table 1). Observations show zonal asymmetries in SH high latitude temperature trends for certain months [Hu and Fu, 2009: Lin et al., 2009], which likely depend on trends and variability in wave driving, not generally captured by climate models [Wang and Waugh, 2012]. As such, we only consider zonal mean trends in the models and data (albeit a sparsely sampled zonal mean for the radiosonde data). By not sampling at the radiosonde locations, this method could bias the sampling of the models to the colder deep vortex. However, we demonstrate below that the "zonal mean" radiosonde trends agree well with those calculated from the MSU TLS data, which has near full coverage of the polar cap. Trends were calculated by linear least squares regression on data binned by month (or season), with the statistical error estimates adjusted to account for serial auto-correlation [as per Santer et al., 2000]. Unless stated, the quoted errors encompass the $95 \%$ confidence interval.

\section{SH temperature trends results}

Figure 2 shows the high latitude $\left(>65^{\circ} \mathrm{S}\right)$ mean temperature trends for the radiosondes, the CMIP3 w/ozone ensemble mean, the CMIP5 ensemble mean, and the CCMVal-2 
ensemble mean, for the period 1969 to 1998 as a function of pressure and month (similar to TS02, their Fig. 1). Trends for the RICH- $\tau$ and RAOBCORE data (not shown) are very similar to RICH-obs, arising from the fact that those datasets use the same stations, and the same break detection algorithm (see Table S1 in the supplementary material for more information).

Both the radiosonde and model data show a strong and significant cooling in the lower stratosphere, extending from $\sim 200-50 \mathrm{hPa}$, and from at least October to December, as also reported by $\mathrm{TS} 02$. The maximum cooling trend occurs for November at approximately $100 \mathrm{hPa}$, although the trends differ both in magnitude and (less so) spatiotemporal patterns. Comparing the radiosonde data shown in the top row of Figure 2, the maximum cooling trend is found in the IUK dataset $(-4.7 \pm 2.8 \mathrm{~K} / \mathrm{dec})$, followed by the RICH-obs dataset $(-4.1 \pm 2.4 \mathrm{~K} / \mathrm{dec})$, with the HadAT2 data showing the weakest cooling $(-3.8 \pm 2.4 \mathrm{~K} / \mathrm{dec})$. These are all stronger values than the $-2.4 \mathrm{~K} / \mathrm{dec}(-7.1 \mathrm{~K} /$ 30 a) trend reported by TS02, but more comparable with the $-3.8 \mathrm{~K} / \mathrm{dec}$ peak value determined from radiosonde data by Thompson and Solomon [2005], although this covers a different period (1979-2003). Like TS02 and Thompson and Solomon [2005], both the IUK and RICH-obs data suggest that the significant lower stratospheric cooling trend persists into March, whereas the trend stops in December with the HadAT2 data.

Why are the trends different between the radiosonde datasets? Figure 1 shows that the $\mathrm{SH}$ mean temperature for each dataset is comprised of different stations, covering different longitude and latitude ranges. At the lower latitudes, the stations may be occasionally sampling air outside of the cold vortex [Hassler et al., 2011a] which weakens the trends derived at these locations. For example, November $100 \mathrm{hPa}$ trends at the South Pole 
station $\left(90^{\circ} \mathrm{S}\right)$ are in the range -6.0 to $-7.1 \mathrm{~K} / \mathrm{dec}$, whereas they are between -2.3 and -2.5 $\mathrm{K} / \mathrm{dec}$ for Casey $\left(66^{\circ} \mathrm{S}\right)$ (see Table S1). Temperature trends at the continent edge may also be impacted by the zonally asymmetric nature of the trend patterns [e.g. Lin et al., 2009], although the degree of asymmetry depends on the month. Hence part of the reason for the stronger cooling seen with the IUK data is that its mean is weighted towards higher latitude stations. However, the RICH-obs, RICH- $\tau$ and RAOBCORE datasets include more stations towards the edge of Antarctica compared to HadAT2, yet they still have stronger cooling trends, suggesting that the spatial distribution of stations cannot explain all the differences between datasets.

Figure 1 also indicates a range of values for the trend at a given station, depending on dataset (see also Table S1). In general, the HadAT2 data show the weakest cooling for a given station. This is particularly the case for McMurdo, Novolazarevsk and Mawson stations, where the HadAT2 data is a factor of 1.5-1.7 lower than the maximum cooling trend. Restricting the RICH-obs data to just the HadAT2 stations (also including SANAE, which does not meet the $<20 \%$ missing data requirement) results in a trend of $-4.7 \pm 2.2$ $\mathrm{K} /$ dec, i.e. more cooling than that calculated from the HadAT2 data. Restricting the RICH-obs data to the IUK locations results in a trend of $-4.6 \pm 2.6 \mathrm{~K} /$ dec, i.e. slightly less cooling than that for the IUK data.

Figure 2 shows that the peak cooling trends for the CMIP5 and CCMVal-2 model ensembles are comparable to the radiosonde data, with November $100 \mathrm{hPa}$ trend values of $-3.5 \pm 0.3 \mathrm{~K} / \mathrm{dec}$ and $-3.8 \pm 0.7 \mathrm{~K} /$ dec respectively. The trends are weaker for the CMIP3 w/ozone ensemble, where the November $100 \mathrm{hPa}$ trend is $-2.7 \pm 0.3 \mathrm{~K} / \mathrm{dec}$. The smaller confidence interval in these trends is due to the substantial reduction in 
interannual variability from averaging several models together, and it is not comparable to the confidence intervals for the observed trends discussed above. Based on the data from TS02, Baldwin et al. [2010] concluded that the CMIP3 w/ozone models had a more favorable comparison with the observed trends than the CCMVal-2 models. However, the broader range of radiosonde trends in Figure 2 suggests that the CCMVal-2 and CMIP5 ensemble means compare more favorably with observations than CMIP3 w/ozone.

In addition to the ozone induced cooling, the RICH-obs and IUK data also show a higher altitude warming trend, occuring after the ozone cooling in IUK and at approximately the same time as the ozone cooling with RICH-obs. A warming trend similar in magnitude and timing to that of IUK is apparent in the CCMVal-2 ensemble mean trend, and (more weakly) in the CMIP5 ensemble mean trend. From the individual models, a warming trend is found in more than half of the CMIP5 models (Figure S2) and in 16 of the 17 CCMVal-2 models (Figure S3), although it is not always significant for either set of models. Manzini et al. [2003] described a similar feature in their CCM study, attributing it to increased downwelling (and compressional warming) due to enhanced gravity wave propagation, itself due to the ozone-induced cooling. Thus, the presence of such a trend could be an indicator of how well models perform in terms of middle atmosphere dynamics, although further study is required.

Figure 3 explores the modeled and observed polar cap $\left(>65^{\circ} \mathrm{S}\right)$ temperatures in more detail. Figure 3(a) shows the time series of November temperature anomalies from 1969 to 2010 (or the latest date for the given data; see Table 1). Figure 3(b) shows the time series of October-January (ONDJ) averaged anomalies for the MSU TLS data, MSU TLS-weighted radiosondes, and MSU TLS-weighted models. The ONDJ mean is used 
here as this corresponds to the months where Baldwin et al. [2010] found that the CCMVal-2 models agreed better with the observed trends of TS02. Notwithstanding that the TS02 trends are smaller in magnitude than those from the other radiosonde datasets, including summer months to calculate the mean trend goes some way to counter model biases in the timing of the SH vortex breakup [Hurwitz et al., 2010; Butchart et al., 2011]. Anomalies are computed relative to a 1979-1999 climatology. Note that using anomalies removes systematic biases, identified as a particular issue for $\mathrm{SH}$ spring temperatures in the CCMVal-2 models [Butchart et al., 2011].

For the individual CCMVal-2 models and observations, both sets of time series show the large year-to-year variability characteristic of springtime lower stratospheric temperatures [e.g., Young et al., 2011], although this is damped in Figure 3(b) by averaging over more months. Time series for the model ensemble means show far less variability, as the noise from individual models tends to cancel. The correlation between the anomalies for the different radiosonde datasets is very high $(r>0.96)$, despite the different stations and different adjustment methods. Furthermore, for Figure 3(b), the correlation between the independent MSU TLS data and radiosondes is also very high $(r>0.93)$. As the MSU dataset has complete zonal coverage (although stopping at $82.5^{\circ} \mathrm{S}$ ), this suggests that the radiosonde datasets are representative of the polar cap temperature, despite their more limited spatial coverage.

Figure 3(c) shows the 1969-1998 trends for the time series in Figure 3(a), including the trends calculated for the individual CCMVal-2 models as well as the radiosonde and model ensemble mean trends discussed above. The error bars encompass the $95 \%$ confidence interval for the trends for all cases except the model ensembles. Here, due to 
aforementioned low variability in the ensemble mean time series, the error bars indicate the range of the trends found from the individual models that comprise the ensemble mean. For CCMVal-2 models with more than one ensemble member (CCSRNIES, CMAM, LMDZrepro, SOCOL and WACCM), the data shown are just from the first simulation ("run 1") so as not to dampen the contribution of interannual variability to the trend uncertainty. The trends calculated for the radiosondes and the CMIP3 w/ozone, CMIP5 and CCMVal-2 ensembles all agree with each other within their uncertainty ranges. The figure also shows the trend calculated using unadjusted ("raw") radiosonde data, for the same stations used by TS02. As seen with the adjusted radiosonde datasets, this trend reflects a stronger cooling than that calculated by TS02 (indicated by the black $\mathrm{X})$, although, again, all are within each other's uncertainty.

Figure 3(d) is similar to 3(c), but shows the 1979-1999 trends for the time series in Figure 3(b), which is the longest period common to all model and observational datasets. Again, the trends for the observations and CMIP3 w/ozone, CMIP5 and CCMVal-2 ensembles all agree within their statistical uncertainty. The close agreement of the MSU TLS and radiosonde trends further underlines the representativeness of the radiosonde data for the SH high latitudes, although the fact that the coverage of the MSU TLS data does not extend to the pole could be impacting the strength of the cooling.

Figures 3(c) and (d) show that trends for the individual CCMVal-2 models cover a wide range of values, wider than that for the other ensembles. Furthermore, while all the trends are negative they are not all significant at the 5\% level. For many CCMVal-2 models, the error bars for the trends are greater than those for the observations, suggesting a larger interannual variability in these models compared to the observations and a topic for 
further study. The range of trends from these models is discussed further in Section 4. That there is a spread of trend estimates is not unique to the CCMVal-2 dataset: figures in the Supplementary Material show individual model trends over 1969-1998 as a function of month and pressure for the CMIP3, CMIP5 and CCVal-2 models, emphasizing the model diversity in this regard.

Figure 3 also includes the time series and trends from the CMIP3 no ozone ensemble, which is markedly weaker than the other ensemble mean trends and the observations. (Note that the "CMIP3 no ozone" trend in Figure 3(d) is not significant; the error bar only indicates that all the models in this ensemble produce a negative trend.) The absence of any significant negative trend for this set of models suggests that cooling from $\mathrm{CO}_{2}$ increases cannot explain the observed trends, confirming the role of ozone depletion as the dominant driver of the $\mathrm{SH}$ lower stratospheric cooling at the end of the $20^{\text {th }}$ century [e.g., Shine et al., 2003; Karpechko et al., 2008].

We also note that the magnitude of the trends depends on the period over which they are computed. Trends calculated from 1969 are generally lower in magnitude (i.e. less cooling) when the end year is later in the record. For example, using the RICH-obs November $100 \mathrm{hPa}$ data, trends are in the range -3.7 to $-4.3 \mathrm{~K} / \mathrm{dec}$ with an end year from 1998 through 2002, and -3.2 to $-3.6 \mathrm{~K} / \mathrm{dec}$ when the end year is from 2003 through 2010. A similar behavior is evident from the CCMVal-2 and CMIP5 ensemble mean time series, where there is a monotonic decrease in the magnitude of the cooling trend when the end year is after 1998. All of these trends are still significant at the 5\% level. 
Visual inspection of the observed time series in Figure 3 does suggest a flattening out of the trend towards the end of the record, although a longer time series would be needed to diagnose a statistically significant change point. While there might be some expectation of a reduction in the cooling trend, since we have now passed the peak CFC concentration [Newman et al., 2007] and ozone loss rates have reduced [Hassler et al., 2011b], there is large year-to-year variability in the stratospheric circulation and hence temperatures. For example, the thus far unique SH sudden stratospheric warming in 2002 [e.g. Newman and Nash, 2005] is a notable anomaly in the record that can impact trend assessments.

\section{The relationship of ozone and temperature trends with CCMVal-2 models}

As well as model-observation comparison for the magnitude of the trend, Baldwin et al. [2010] considered how the austral spring temperature and ozone trends were related to one another, in the individual models and in observations. They reported (their Figure 10.13) that CCMs qualitatively reproduced the observed correlation between weaker (stronger) ozone depletion and weaker (stronger) $100 \mathrm{hPa}$ cooling trends. But they also suggested, based on TS02 and Halley station total ozone column observational data, that the models overestimated the cooling for a given ozone loss. We revisit their analysis in this section, using the expanded set of observations from the radiosonde datasets as well as an expanded set of ozone column data.

Figure 4 shows the relationship between the September-December (SOND) ozone column trend and ONDJ temperature trends for the individual CCMVal-2 models, the CCMVal-2 ensemble mean, and observations. Figure 4(a) shows the relationship for the 
1969-1998 trends, using the $100 \mathrm{hPa}$ temperature [as per Baldwin et al., 2010], and Figure 4(b) shows the relationship for the 1979-1999 trends, using MSU TLS and MSU TLS-weighted temperature data. The MSU TLS data are useful for this case as there is substantial overlap between the weighting function and the vertical region of greatest Antarctic ozone depletion. Observed ozone column trends are from the mean of the four Antarctic ozonesonde stations with the longest records: Faraday/Vernadsky $\left(65^{\circ} \mathrm{S}\right.$, $\left.64^{\circ} \mathrm{W}\right)$, Syowa $\left(69^{\circ} \mathrm{S}, 40^{\circ} \mathrm{E}\right)$, Halley $\left(76^{\circ} \mathrm{S}, 27^{\circ} \mathrm{W}\right)$, and South Pole $\left(90^{\circ} \mathrm{S}, 25^{\circ} \mathrm{W}\right)$ [as per Hassler et al., 2011a].

Error bars on the observations show the range of the trend values for the different temperature datasets (horizontal bars) and different ozonesonde stations (vertical bars).

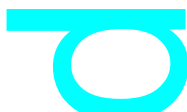
All the observed trends are significant at the 5\% level. Error bars on the CCMVal-2 ensemble mean trend indicate the $95 \%$ confidence interval for the mean, determined from the spread of the trends from the individual models. Acknowledging the distinctive estimates of statistical uncertainty in the modeled and observed trends, the error bars for the observations and CCMVal-2 ensemble mean trend overlap in both panels of Figure 4. This further strengthens the case made in the previous section, that the CCMVal-2 ensemble mean matches the observations within the uncertainty of both, for both ozone and temperature.

Individual CCMVal-2 models show a large scatter in their ozone and temperature trends, as also shown in Figure 3. However, the dashed line in each panel of Figure 4 indicates the positive (and significant) relationship between the modeled trends in lower stratospheric temperatures and ozone column. Note that the regression is forced through the origin, i.e. assuming zero temperature trend for zero ozone loss. If the regression is 
not forced through zero, the resulting intercept suggests a positive temperature trend for ozone loss less than $20 \mathrm{DU} / \mathrm{dec}$, which may not be physical. The regression coefficients for each panel are very similar. The regression coefficient for Figure 4(a) is $12.0 \pm 1.8$ DU $\mathrm{dec}^{-1} / \mathrm{K} \mathrm{dec}^{-1}$, and for Figure 4(b) it is $12.1 \pm 2.3 \mathrm{DU} \mathrm{dec}^{-1} / \mathrm{K} \mathrm{dec}^{-1}$; i.e., an ozone trend of $12 \mathrm{DU} / \mathrm{dec}$ is predicted to be accompanied by a temperature trend of $1 \mathrm{~K} / \mathrm{dec}$.

The gray shaded area in Figure 4 shows the 95\% confidence interval for the linear regression, estimated from the variance of the regression residuals [e.g., see Wilks, 2006]. The area estimates the uncertainty in the relationship between the trends in ozone column and lower stratospheric temperature, as derived from the models: i.e., if we have a certain trend in the ozone column, the gray indicates where we are $95 \%$ certain that the corresponding temperature trend will lie (or vice versa). While the observed trends in Figure 4 sit below the regression line, and therefore suggest a smaller temperature trend for a given ozone change, they are within the shaded area. This would suggest that, at the 5\% level, the CCMVal-2 models do not produce a stronger cooling for a given ozone depletion compared to observations. Note that the observations still lie within the $95 \%$ confidence interval if the regression is not forced through the origin. (Interestingly, the 95\% confidence interval does not include the origin if the regression for Figure $4 \mathrm{a}$ is not forced through it.)

Finally, Figure 4(a) also indicates the temperature trend calculated by TS02. For ONDJ their estimated trend falls within the range of those estimated from the other datasets, but only due to the inclusion of the HadAT2 data, which has a weaker cooling trend than the other radiosonde datasets. From Figure 2 we see that the HadAT2 cooling trend does not continue through the austral summer, as it does for the IUK and RICH-obs data. 
Restricting the RICH-obs data to the HadAT2 stations does not change the monthpressure trend pattern markedly from the full RICH-obs data in Figure 2(a), suggesting that the more limited cooling in the HadAT2 data is related to the adjustment method, rather than the spatial distribution of the stations.

\section{Summary and conclusions}

We have presented late $20^{\text {th }}$ century, high latitude Southern Hemisphere (SH) stratospheric temperature trends from several radiosonde datasets, satellite measurements, and multi-model ensemble data from climate and chemistry-climate models. Except for models that do not include ozone depletion, all the trends show strong cooling during austral spring and summer, peaking in November at around $100 \mathrm{hPa}$. While the observed cooling is dependent on the dataset, the magnitudes of the trends calculated here are more than 50\% stronger than those presented by Thompson and Solomon [2002] (TS02), often used as a benchmark for modeling studies. However, once the statistical uncertainties are taken into account, the trends from the multi-model ensembles and observations (including TS02) agree with one another. Overall, the results suggest that there is not a systematic bias towards excessive cooling in the ensemble mean SH lower stratosphere temperatures determined from the latest generation of stratospheric chemistry-climate models $(\mathrm{CCMs})$. Furthermore, our results also suggest that ensemble mean temperature trends determined from climate models also compare well to observed trends, provided that the models include some representation of late $20^{\text {th }}$ century ozone depletion [Cordero and Forster, 2006]. 
While trends calculated from ensemble mean temperatures match observed trends well, trends from the individual models show a large spread. Despite including the drivers of ozone depletion, some of the CCMVal-2 models do not have significant austral spring temperature trends. This range of model skill for stratospherically relevant parameters in the CCMs has been explored in several other studies [e.g. Gettelman et al., 2010; Hegglin et al., 2010; Butchart et al., 2011], and several shortcomings have been identified. In particular, Butchart et al. [2011] highlighted a pervasive poor performance of the models for the SH during austral spring, and several studies have indicated the large range of modeled ozone trends [Eyring et al., 2006; Austin et al., 2009; Austin et al., 2010]. For the climate models, the spread of the trends is generally less, likely due to the prevalence of a prescribed ozone dataset rather than the more complex online calculation of ozone in the CCMs. Nevertheless, for the CCMs there is a significant positive linear relationship between the magnitude of the cooling trend and the magnitude of the ozone depletion, and the observed temperature and ozone trends appear to conform to the same relationship, within the statistical uncertainty. I.e., our results suggest that the models do not systematically overestimate the cooling for a given ozone depletion.

Overall, we would recommend that multiple temperature datasets are used to understand the evolution of stratospheric temperature, both for observational studies and model evaluation, echoing the similar sentiments of Free [2010], Thorne et al. [2010], and Calvo et al. [2012]. The latter study is especially pertinent here, as they evaluated SH late- $20^{\text {th }}$ century temperature trends in a CCM using a range of datasets and found that the modeled cooling trend agreed better with datasets other than TS02.

\section{Acknowledgements}

(C) 2013 American Geophysical Union. All rights reserved. 
We thank Greg Bodeker, Nathan Gillett, Susan Solomon and Dave Thompson for discussion and useful input. We thank Steve Sherwood and the Met Office for the provision of the IUK (www.ccrc.unsw.edu.au/staff/profiles/sherwood/radproj/index.html) and HadAT2 (www.metoffice.gov.uk/hadobs) radiosonde datasets, respectively. We acknowledge the WCRP's (World Climate Research Programme) Working Group on Coupled Modelling, which is responsible for CMIP, and we thank the climate modeling groups (as listed in Tables S2 and S3 of this paper) for producing and making available their model output. For CMIP, the U.S. Department of Energy's Program for Climate Model Diagnosis and Intercomparison provides coordinating support and led development of software infrastructure in partnership with the Global Organization for Earth System Science Portals. We acknowledge the Chemistry- Climate Model Validation (CCMVal) Activity of WCRP's SPARC (Stratospheric Processes and their Role in Climate) project, and the participating model groups (as listed in Table S4 of this paper), for organizing and coordinating the CCMVal-2 activity, and the British Atmospheric Data Centre (BADC) for collecting and archiving the model output. Natalia Calvo was partially supported by the Advanced Study Program from the National Center for Atmospheric Research. The National Center for Atmospheric Research is operated by the University Corporation for Atmospheric Research under sponsorship of the National Science Foundation. Leopold Haimberger was supported by the Austrian Science Funds (FWF) project P21772-N22. We thank Alexey Karpechko, Darryn Waugh and an anonymous reviewer for their comments on an earlier version of the manuscript.

\section{References}


Austin, J., et al. (2009), Coupled chemistry climate model simulations of stratospheric temperatures and their trends for the recent past, Geophysical Research Letters, 36(13), L13809.

Austin, J., et al. (2010), Chemistry-climate model simulations of spring Antarctic ozone, Journal of Geophysical Research, 115, D00M11.

Butchart, N., et al. (2011), Multimodel climate and variability of the stratosphere, Journal of Geophysical Research, 116(D5), D05102.

Cai, W., and T. Cowan (2007), Trends in Southern Hemisphere Circulation in IPCC AR4 Models over 1950-99: Ozone Depletion versus Greenhouse Forcing, Journal Of Climate, 20, 681-693.

Calvo, N., R. R. Garcia, D. R. R. Marsh, M. J Mills, D. E. Kinnison, and P. J. Young (2012), Reconciling modeled and observed temperature trends over Antarctica, Geophysical Research Letters.

Cionni, I., V. Eyring, J. F. Lamarque, W. J. Randel, D. S. Stevenson, F. Wu, G. E. Bodeker, T. G. Shepherd, D. T. Shindell, and D. W. Waugh (2011), Ozone database in support of CMIP5 simulations: results and corresponding radiative forcing, Atmospheric Chemistry and Physics Discussions, 11(4), 10875-10933.

Cordero, E. C., and P. M. Forster (2006), Stratospheric variability and trends in models used for the IPCC AR4, Atmospheric Chemistry And Physics, 6, 5369-5380.

Dee, D. P., et al. (2011), The ERA-Interim reanalysis: configuration and performance of the data assimilation system, Quarterly Journal Of The Royal Meteorological Society, 137(656), 553-597.

Eyring, V., M. P. Chipperfield, M. A. Giorgetta, D. E. Kinnison, E. Manzini, K. Matthes, P. A. Newman, S. Pawson, T. G. Shepherd, and D. W. Waugh (2008), Overview of the new CCMVal reference and sensitivity simulations in support of upcoming ozone and climate assessments and the planned SPARC CCMVal, SPARC Newsletter, 30, 20-26.

Eyring, V., et al. (2006), Assessment of temperature, trace species, and ozone in chemistry-climate model simulations of the recent past,, Journal of Geophysical Research, 111, D22308.

Free, M. (2011), The Seasonal Structure of Temperature Trends in the Tropical Lower Stratosphere, Journal Of Climate, 24(3), 859-866.

Garny, H., M. Dameris, and A. Stenke (2009), Impact of prescribed SSTs on climatologies and long-term trends in CCM simulations, Atmospheric Chemistry And Physics, 9(16), 6017-6031.

Gettelman, A., et al. (2010), Multimodel assessment of the upper troposphere and lower stratosphere: Tropics and global trends, Journal of Geophysical Research, 115(null), D00M08.

Gillett, N. P., and D. W. Thompson (2003), Simulation of recent Southern Hemisphere climate change, Science, 302(5643), 273-275.

Gillett, N. P., et al. (2011), Attribution of observed changes in stratospheric ozone and temperature, Atmospheric Chemistry And Physics, 11(2), 599-609.

Haimberger, L., C. Tavolato, and S. Sperka (2008), Toward Elimination of the Warm Bias in Historic Radiosonde Temperature Records-Some New Results from a Comprehensive Intercomparison of Upper-Air Data, Journal Of Climate, 21(18), 45874606. 
Haimberger, L., C. Tavolato, and S. Sperka (2012), Homogenization of the global radiosonde temperature dataset through combined comparison with reanalysis background series and neighboring stations, Journal Of Climate, 120608133708009. Hassler, B., G. E. Bodeker, S. Solomon, and P. J. Young (2011a), Changes in the polar vortex: Effects on Antarctic total ozone observations at various stations, Geophysical Research Letters, 38, L01805.

Hassler, B., J. S. Daniel, B. J. Johnson, S. Solomon, and S. J. Oltmans (2011b), An assessment of changing ozone loss rates at South Pole: Twenty-five years of ozonesonde measurements, Journal of Geophysical Research, 116(D22), D22301-.

Hegglin, M. I., et al. (2010), Multimodel assessment of the upper troposphere and lower stratosphere: Extratropics, Journal of Geophysical Research, 115, D00M09.

Hurwitz, M. M., P. A. Newman, F. Li, L. D. Oman, O. Morgenstern, P. Braesicke, and J. A. Pyle (2010), Assessment of the breakup of the Antarctic polar vortex in two new chemistry-climate models, Journal of Geophysical Research, 115(D7), D07105.

Kang, S. M., L. M. Polvani, J. C. Fyfe, and M. Sigmond (2011), Impact of Polar Ozone Depletion on Subtropical Precipitation, Science, 332, 951-954.

Karpechko, A. Y., N. P. Gillett, G. J. Marshall, and A. A. Scaife (2008), Stratospheric influence on circulation changes in the Southern Hemisphere troposphere in coupled climate models, Geophysical Research Letters, 35(20), L20806.

Lin, P., Q. Fu, S. Solomon, and J. M. Wallace (2009), Temperature Trend Patterns in Southern Hemisphere High Latitudes: Novel Indicators of Stratospheric Change, Journal Of Climate, 22(23), 6325-6340.

Manzini, E., B. Steil, C. Brühl, M. A. Giorgetta, and K. Krüger (2003), A new interactive chemistry-climate model: 2 . Sensitivity of the middle atmosphere to ozone depletion and increase in greenhouse gases and implications for recent stratospheric cooling, Journal of Geophysical Research, 108(D14), 4429-.

Mclandress, C., and T. G. Shepherd (2009), Simulated Anthropogenic Changes in the Brewer-Dobson Circulation, Including Its Extension to High Latitudes, Journal Of Climate, 22(6), 1516.

Mears, C. A., and F. J. Wentz (2009), Construction of the Remote Sensing Systems V3.2 Atmospheric Temperature Records from the MSU and AMSU Microwave Sounders, Journal of Atmospheric and Oceanic Technology, 26(6), 1040-1056.

Meehl, G. A., C. Covey, K. E. Taylor, T. Delworth, R. J. Stouffer, M. Latif, B. Mcavaney, and J. F. B. Mitchell (2007), The WCRP CMIP3 Multimodel Dataset: A New Era in Climate Change Research, Bulletin of the American Meteorological Society, 88(9), 1383-1394.

Miller, R. L., G. A. Schmidt, and D. T. Shindell (2006), Forced annular variations in the 20th century Intergovernmental Panel on Climate Change Fourth Assessment Report models, Journal of Geophysical Research, 111(D18), D18101.

Morgenstern, O., et al. (2010), Review of the formulation of present-generation stratospheric chemistry-climate models and associated external forcings, Journal of Geophysical Research, 115(null), D00M02.

Newman, P. A., and E. R. Nash (2005), The Unusual Southern Hemisphere Stratosphere Winter of 2002, Journal Of The Atmospheric Sciences, 62(3), 614-628. 
Newman, P. A., J. S. Daniel, D. W. Waugh, and E. R. Nash (2007), A new formulation of equivalent effective stratospheric chlorine (EESC), Atmospheric Chemistry And Physics, 7(17), 4537-4552.

Polvani, L. M., D. W. Waugh, G. J. P. Correa, and S.-W. Son (2011), Stratospheric Ozone Depletion: The Main Driver of Twentieth-Century Atmospheric Circulation Changes in the Southern Hemisphere, Journal Of Climate, 24(3), 795-812.

Randel, W. J., and F. Wu (1999), Cooling of the Arctic and Antarctic Polar Stratospheres due to Ozone Depletion, Journal Of Climate, 12(5), 1467-1479.

Randel, W. J., et al. (2009), An update of observed stratospheric temperature trends, Journal of Geophysical Research, 114(D2), D02107-.

Santer, B. D., T. M. L. Wigley, J. S. Boyle, D. J. Gaffen, J. J. Hnilo, D. Nychka, D. E. Parker, and K. E. Taylor (2000), Statistical significance of trends and trend differences in layer-average atmospheric temperature time series, Journal of Geophysical Research, 105(D6), 7337-7356.

Sherwood, S. C., C. L. Meyer, R. J. Allen, and H. A. Titchner (2008), Robust Tropospheric Warming Revealed by Iteratively Homogenized Radiosonde Data, Journal Of Climate, 21(20), 5336-5352.

Shine, K. P., et al. (2003), A comparison of model-simulated trends in stratospheric temperatures, Quarterly Journal Of The Royal Meteorological Society, 129(590), 15651588.

Solomon, S. (1999), Stratospheric Ozone Depletion: A Review of Concepts and History, Reviews of Geophysics, 37, 275-316.

Son, S. W., et al. (2010), Impact of stratospheric ozone on Southern Hemisphere circulation change: A multimodel assessment, Journal of Geophysical Research, 115, D00M07.

Taylor, K. E., R. J. Stouffer, and G. A. Meehl (2012), An Overview of CMIP5 and the Experiment Design, Bulletin of the American Meteorological Society, 93, 485-498.

Thompson, D. W., and S. Solomon (2002), Interpretation of Recent Southern Hemisphere Climate Change, Science, 296(5569), 895-899.

Thompson, D. W. J., and S. Solomon (2005), Recent Stratospheric Climate Trends as Evidenced in Radiosonde Data: Global Structure and Tropospheric Linkages, Journal Of Climate, 18(22), 4785-4795.

Thompson, D. W. J., S. Solomon, P. J. Kushner, M. H. England, K. M. Grise, and D. J. Karoly (2011), Signatures of the Antarctic ozone hole in Southern Hemisphere surface climate change, Nature Geoscience, 4(11), 741-749.

Thorne, P. W., J. R. Lanzante, T. C. Peterson, D. J. Seidel, and K. P. Shine (2010), Tropospheric temperature trends: history of an ongoing controversy, Wiley Interdisciplinary Reviews: Climate Change, 2(1), 66-88.

Thorne, P. W., D. E. Parker, S. F. B. Tett, P. D. Jones, M. McCarthy, H. Coleman, and P. Brohan (2005), Revisiting radiosonde upper air temperatures from 1958 to 2002, Journal of Geophysical Research, 110(D18), D18105-.

Young, P. J., D. W. J. Thompson, K. H. Rosenlof, S. Solomon, and J.-F. Lamarque (2011), The seasonal cycle and interannual variability in stratospheric temperatures and links to the Brewer-Dobson circulation: An analysis of MSU and SSU data, Journal Of Climate, 110713113105003. 
Table 1. Summary of radiosonde, satellite and model data used in this study.

\begin{tabular}{|c|c|c|c|c|}
\hline Data & Abbreviation & Stations ${ }^{\mathrm{a}}$ & $\begin{array}{l}\text { Period } \\
\text { covered }^{\mathrm{b}}\end{array}$ & Reference \\
\hline $\begin{array}{l}\text { Hadley Centre } \\
\text { Atmospheric } \\
\text { Temperatures, ver. } 2\end{array}$ & HadAT2 & 7 & $1969-2010$ & Thorne et al. [2005] \\
\hline Iterative Universal Kriging & IUK & 5 & 1969-2005 & Sherwood et al. [2008] \\
\hline $\begin{array}{l}\text { Radiosonde Observation } \\
\text { Correction } \\
\text { Reanalysis, ver. 1.5 }\end{array}$ & RAOBCORE & 11 & $1969-2010$ & $\begin{array}{l}\text { Haimberger et al. } \\
{[2008]}\end{array}$ \\
\hline $\begin{array}{l}\text { Radiosonde Innovation } \\
\text { Composite } \\
\text { Homogenization (obs), ver. }\end{array}$ & RICH-obs & 11 & $1969-2010$ & $\begin{array}{l}\text { Haimberger et al. } \\
{[2012]}\end{array}$ \\
\hline $\begin{array}{l}\text { Radiosonde Innovation } \\
\text { Composite }\end{array}$ & RICH- $\tau$ & 11 & $1969-2010$ & $\begin{array}{l}\text { Haimberger et al. } \\
{[2012]}\end{array}$ \\
\hline Raw radiosonde data & Raw & 11 & $1969-2010$ & $\begin{array}{l}\text { IGRA }^{\mathrm{c}} \text {, and ERA-40 } \\
\text { and ERA-Interim } \\
\text { observation input [Dee } \\
\text { et al., 2011] }\end{array}$ \\
\hline
\end{tabular}




\begin{tabular}{|l|l|l|l|l|}
\hline $\begin{array}{l}\text { MSU lower stratosphere } \\
\text { temperatures, Remote } \\
\text { Systems Sensing, ver. 3.3 }\end{array}$ & MSU TLS & & $1979-2010$ & Mears and Wentz [2009] \\
\hline CCMVal-2 historical & CCMVal-2 & & $1969-2000$ & Morgenstern et al. \\
(REF-B1) simulation & & & \\
model output & [2010] & \\
\hline CMIP3 historical (20C3M) & CMIP3 & & $1969-1999$ & Meehl et al. [2007] \\
simulation model output & & & & \\
\hline CMIP5 historical (hist) & CMIP5 & & $1969-2005$ & Taylor et al. [2012] \\
simulation model output & & & & \\
\hline
\end{tabular}

${ }^{\mathrm{a}}$ For radiosonde data, the number of stations south of $65^{\circ} \mathrm{S}$.

${ }^{\mathrm{b}}$ The start date refers to first year used in this study. For CCMVal-2, CMIP3 and CMIP5, the end date is the year for which all models still have output.

${ }^{\mathrm{c}}$ Integrated Global Radiosonde Archive (http://www.ncdc.noaa.gov/oa/climate/igra/) 

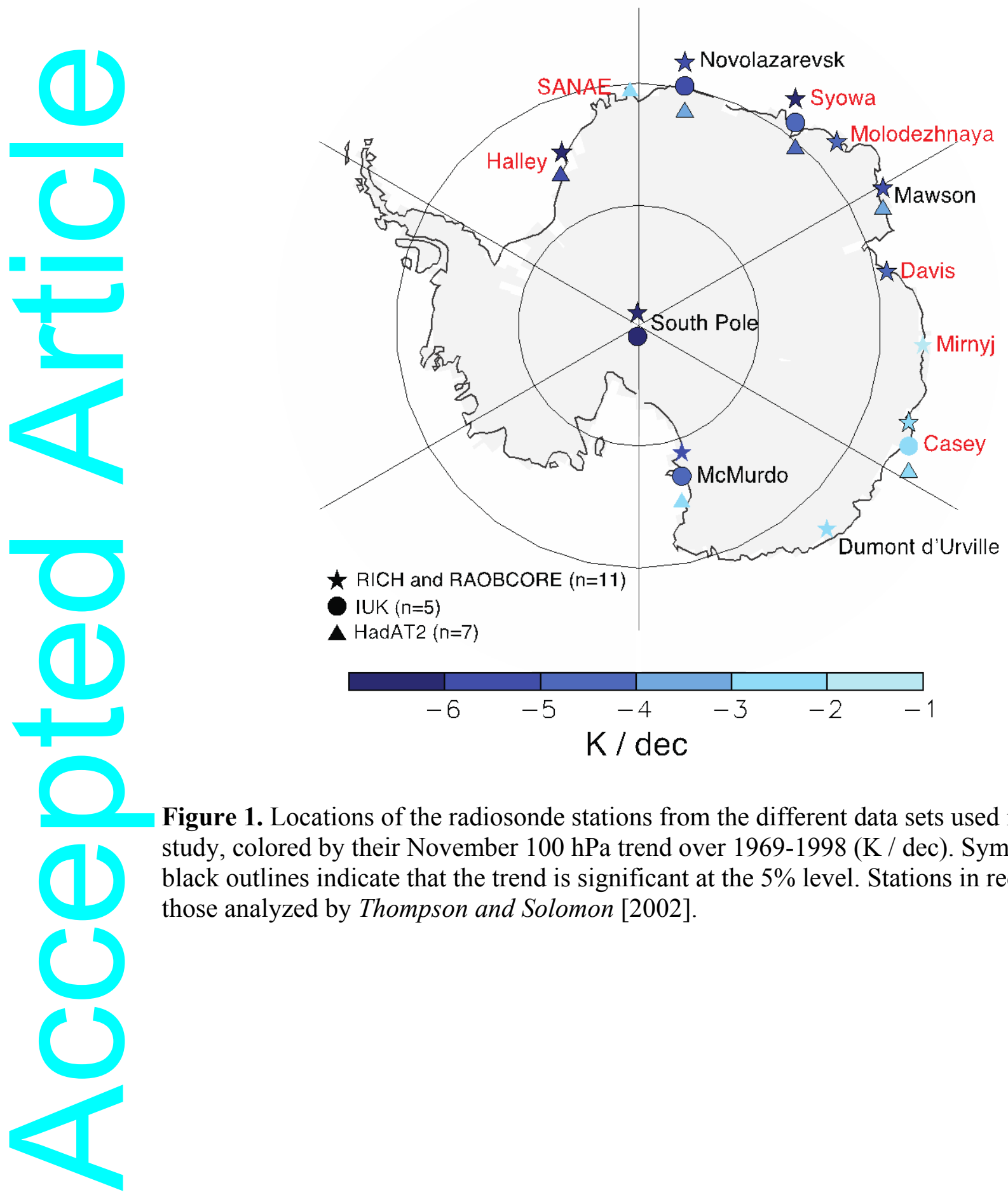

Figure 1. Locations of the radiosonde stations from the different data sets used in this study, colored by their November $100 \mathrm{hPa}$ trend over 1969-1998 (K / dec). Symbols with black outlines indicate that the trend is significant at the 5\% level. Stations in red are those analyzed by Thompson and Solomon [2002]. 
(a) RICH-obs

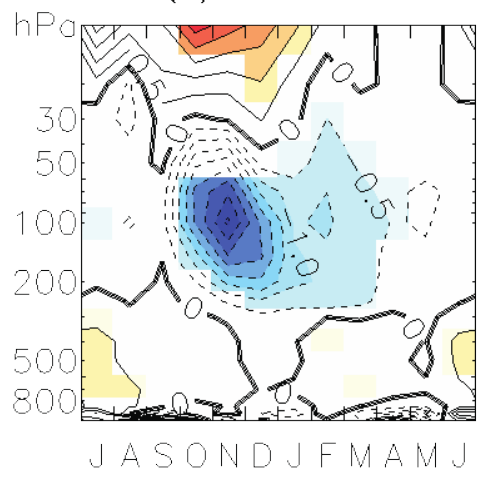

(d) CMIP3 w/ozone

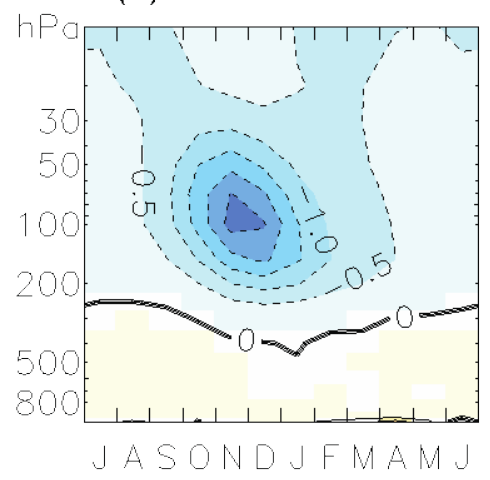

(b) HadAT2

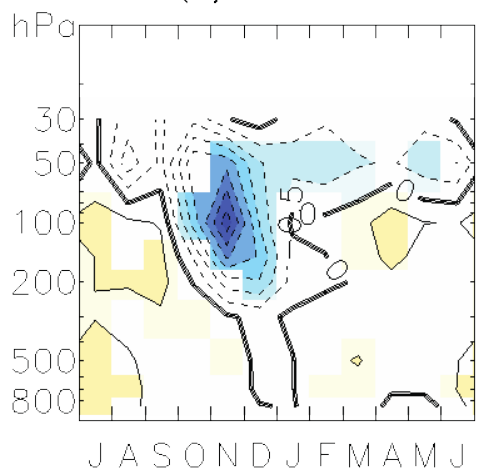

(e) CMIP5

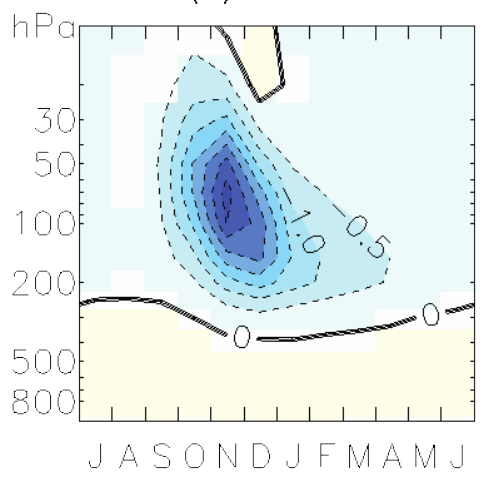

(c) IUK

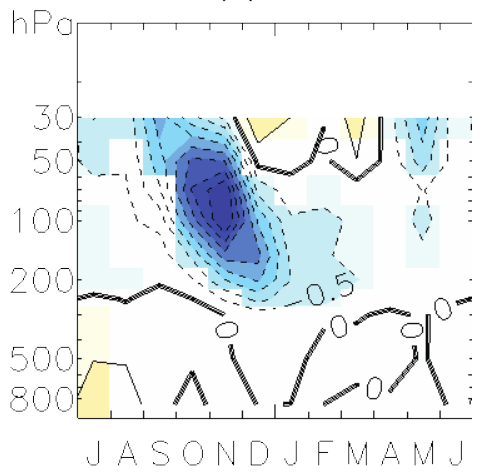

(f) CCMVal-2

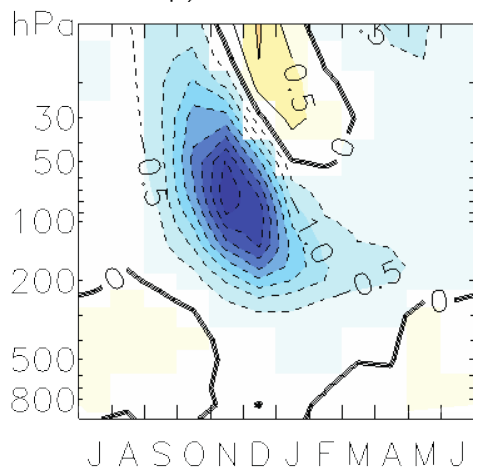

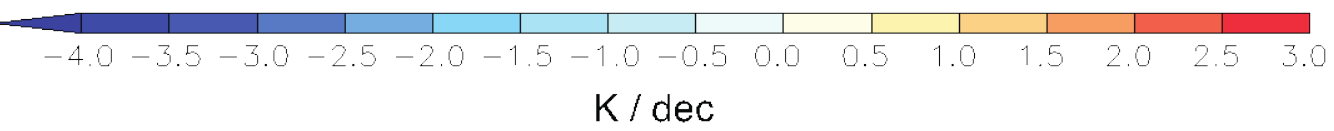

Figure 2. Southern hemisphere high latitude temperature trends over 1969-1998 (K / $\mathrm{dec}$ ), as a function of month and pressure. Trends are shown for (a) RICH-obs, (b) HadAT2 and (c) IUK radiosondes, and the ensemble means of (d) the CMIP3 models (just those with ozone depletion), (e) the CMIP5 models and (f) the CCMVal-2 models. Radiosonde trends are calculated using the average of the temperatures for the stations poleward of $65^{\circ} \mathrm{S}$, and model trends are calculated from the zonal mean temperatures for region poleward of $65^{\circ} \mathrm{S}$. Color-filled contours indicate that the trend is significant at the $5 \%$ level. Contour spacing is $0.5 \mathrm{~K} / \mathrm{dec}$. 

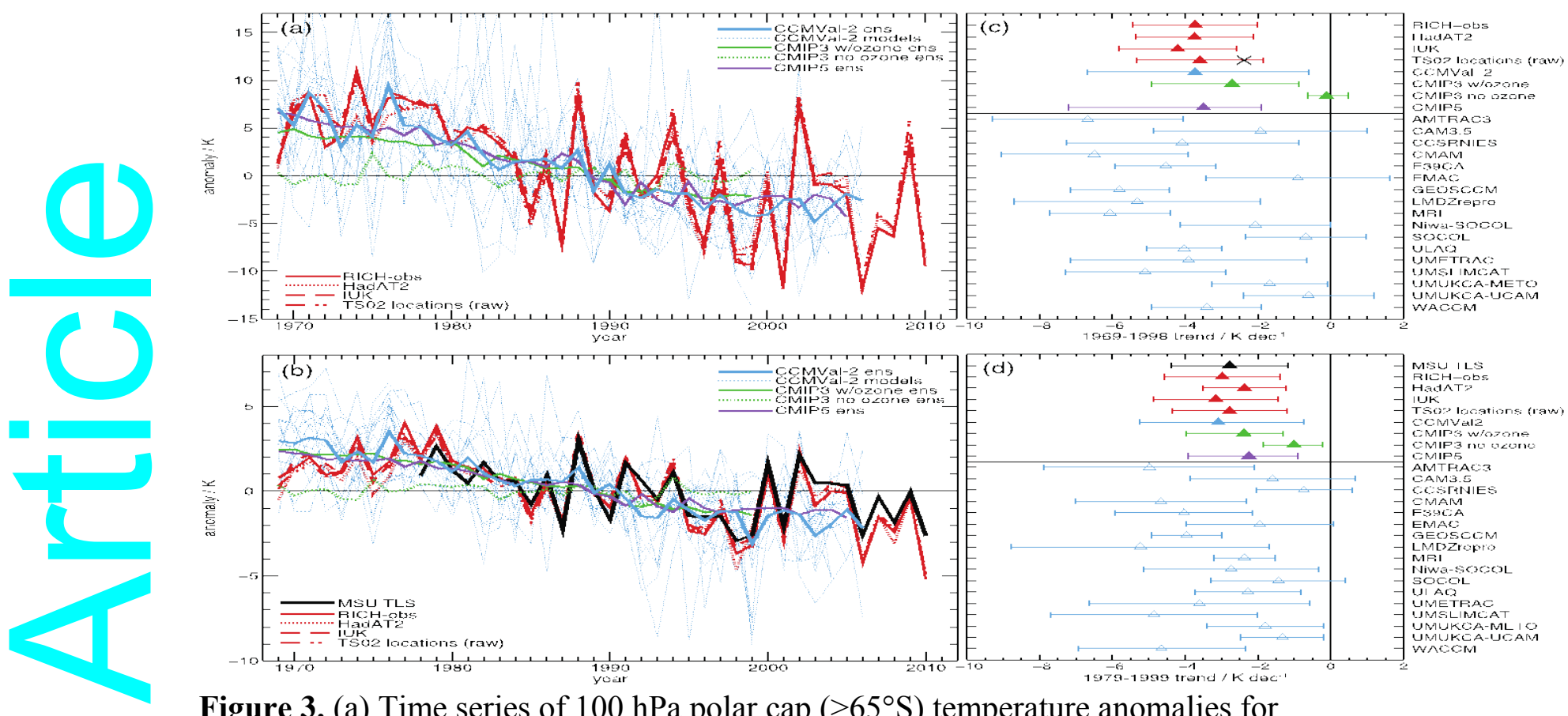

Figure 3. (a) Time series of $100 \mathrm{hPa}$ polar cap $\left(>65^{\circ} \mathrm{S}\right)$ temperature anomalies for November, for the different radiosonde datasets and the unadjusted radiosondes at the Thompson and Solomon [2002] locations (red), the CMIP3 "w/ozone" and "no ozone" ensemble means (green), the CMIP5 ensemble mean (purple), and the CCMVal-2 models and ensemble mean (blue). (b) As (a), but time series of MSU TLS-weighted temperature anomalies for the October-January average and including MSU TLS data (black). (c) Trends for the anomalies in (a) over the period 1969-1998 (K/ dec). (d) Trends for the anomalies in (b) over the period 1979-1999 (K/ dec). For (c) and (d) the error bars indicate the 95\% confidence interval for the trends, except for the CMIP3, CMIP5 and CCMVal-2 ensemble means where it indicates the range of the trends from the individual models. The black cross on the "TS02 locations (raw)" trend in (c) indicates the trend reported by Thompson and Solomon [2002]. 


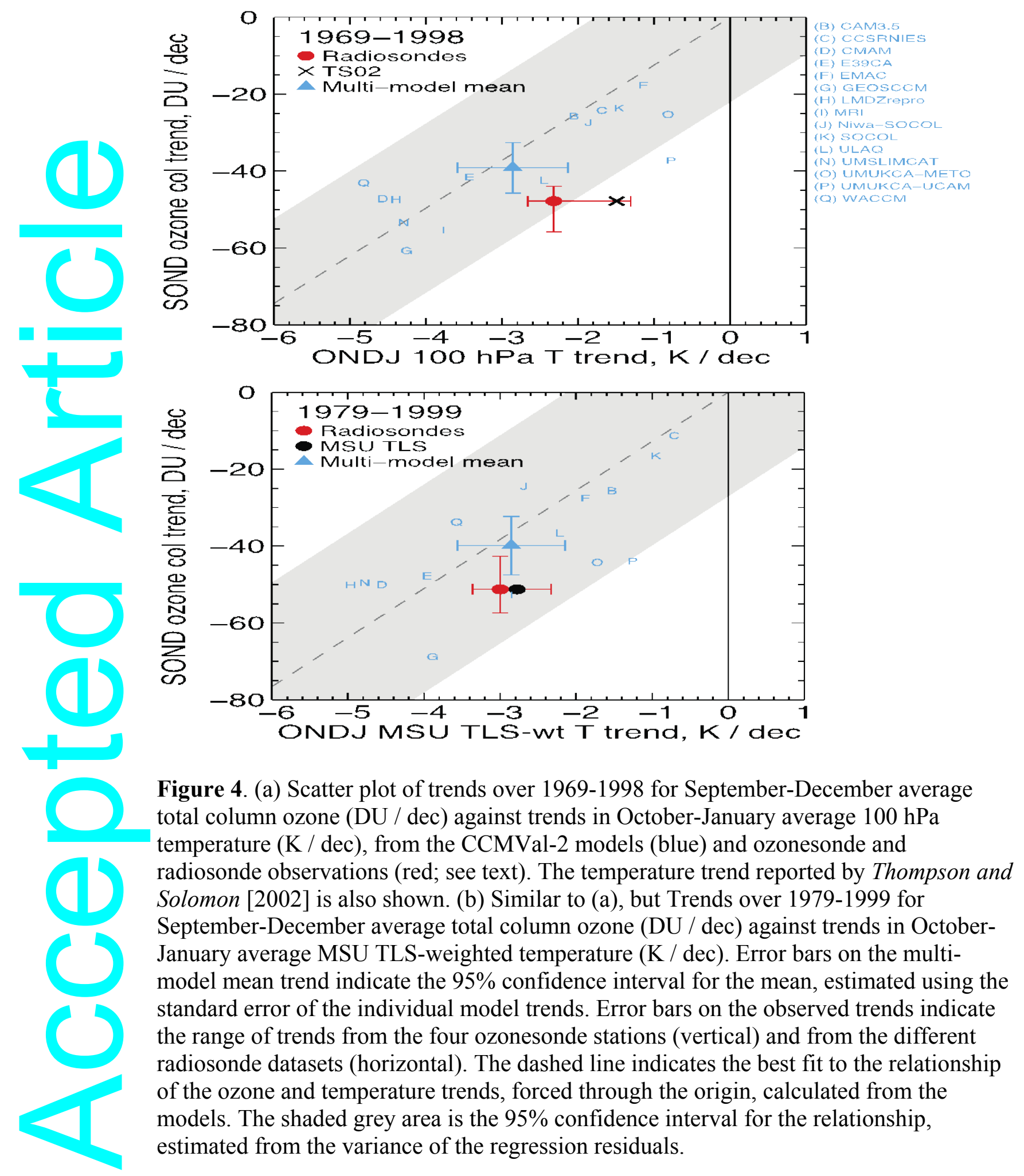

(C) 2013 American Geophysical Union. All rights reserved. 